Research Article

\title{
Evaluation of Enterprise Management Innovation in Manufacturing Industry Using Fuzzy Multicriteria Decision-Making under the Background of Big Data
}

\author{
Yi Yan ${ }^{1}{ }^{1}$ and Dejiang Chu $\mathbb{D}^{2}$ \\ ${ }^{1}$ Linzhou College of Architectural Technology, Anyang, Henan, China \\ ${ }^{2}$ School of Public Administration and Society, Jiangsu Normal University, Xuzhou, Jiangsu 221116, China \\ Correspondence should be addressed to Dejiang Chu; cdj@jsnu.edu.cn
}

Received 3 August 2021; Revised 14 September 2021; Accepted 16 September 2021; Published 10 November 2021

Academic Editor: Zaoli Yang

Copyright (c) 2021 Yi Yan and Dejiang Chu. This is an open access article distributed under the Creative Commons Attribution License, which permits unrestricted use, distribution, and reproduction in any medium, provided the original work is properly cited.

\begin{abstract}
The manufacturing industry has always been in the dominant position in the development of China's national economy. The present industrial structure and development mode of the manufacturing industry are in a critical transformation period. This study aims to explore the problems in the management of manufacturing enterprises in the era of big data. Supplier management is the top priority of manufacturing enterprise management. Regarding the performance appraisal of manufacturing enterprises, the management data of large manufacturing enterprises are collected by questionnaire. 226 questionnaires are issued, and 203 valid questionnaires are collected. The performance appraisal management of manufacturing enterprises is analyzed based on the analytic hierarchy process (AHP) of fuzzy multicriteria decision-making, and the evaluation system of enterprise performance management is established. The results show that the average value of the four indexes of enterprise marketing management, enterprise research and development (R\&D) support, enterprise R\&D achievement transformation efficiency, and enterprise production innovation is higher than 3.731, indicating that large manufacturing enterprises quite support marketing, $R \& D$, and production innovation. This exploration can provide a theoretical basis for improving the management innovation ability of manufacturing enterprises and also has great reference value for expanding the market competitiveness of manufacturing enterprises.
\end{abstract}

\section{Introduction}

The manufacturing industry, as a national economy, is crucial for building a well-off society in an all-round way in China [1]. At present, the report of China's manufacturing industry proposes to transform the traditional mode of manufacturing industry into a new sustainable development mode of reducing energy consumption and pollution. The manufacturing industry is facing a key transformation, which attaches importance not only to the technological innovation ability, but also to the management innovation ability of enterprises as the key to improvement [2]. The whole process of management decision-making of manufacturing enterprises is deeply affected by the risks and challenges in the era of big data. It is essential to improve the resource information digitization and promote the implementation of enterprise management innovation strategy, thus enhancing the market competitiveness of enterprises. The innovation of enterprise management systems needs effective information data and technical knowledge. The popularity of big data technology and cloud computing makes more enterprises begin to focus on using big data to obtain these resources [3]. Using big data technology for decision-making and prediction has become a new way to promote the development of enterprise management innovation, which can meet the market demand. To maintain market competitiveness, enterprises adopt big data to obtain information resources, such as the new trend of technology development, new concepts of products and services, and new customer and supplier need. China's energy security 
and environmental pollution problems are becoming increasingly prominent at present. Su and $\mathrm{Yu}$ [4] put forward suggestions to improve pollution control performance through spatial econometric analysis of regional pollution control performance. The research shows that employee spatial agglomeration positively impacts pollution control, which also has great reference value for evaluating the management innovation ability of manufacturing enterprises under the background of big data. Using big data capability as enterprise innovation performance evaluation index can develop technology innovation performance evaluation system to meet the needs of enterprise management, and develop technology innovation of science and technology innovation enterprises in the new era.

The theory of fuzzy sets is significant in the field of mathematics and has been widely used in multiple aspects of real-life since it was put forward [5]. A relatively complete fuzzy topology with obvious characteristics has been formed until the 1990s. Multicriteria decision-making (MCDM) can help decision-makers to choose multiple objectives or multiple attributes. It has developed rapidly because of its accurate and effective characteristics since it was proposed. At present, the research of multicriteria group decisionmaking has become a crucial part of the field of management decision-making.

Data are collected through the questionnaire in the era of big data. The evaluation of management innovation ability of Chinese manufacturing enterprises is studied, to intuitively reflect the level and stage of management innovation of enterprises, find out the shortcomings of enterprise management innovation in time, and point out the direction for enterprises to improve the management innovation ability.

\section{The Evaluation System of Manufacturing Enterprise Management Innovation Based on Fuzzy MCDM}

\subsection{Development Characteristics of Manufacturing} Enterprises. The process of transforming various raw material resources into new products through chemical or physical changes with the assistance of human, machine, and natural forces is called manufacturing. The manufacturing industry includes machinery manufacturing, production and processing of petroleum, food, toys, steel, and textile [6]. The development of Chinese manufacturing enterprises has the following characteristics.

\subsubsection{The Management Is Backward and the Economies of} Scale Are Poor. The economies of scale in the foreign manufacturing industry are the most significant. However, the comprehensive quality of entrepreneurs and managers of private enterprises in China is not high, and the organizational structure of enterprises is loose, leading to the lack of advanced management skills.

2.1.2. Enterprises Lack Innovation Ability and Market Competitiveness. Chinese manufacturing enterprises can only rely on human capital advantages to enter the market competition due to the lack of funds and innovative technology support. In the long run, the consequence of low-cost labor advantage is that Chinese enterprises gradually lose their core technology, and the key technology mainly depends on imports.

2.1.3. The Utilization Rate of Resources Is Not High. The lowend processing of the world's manufacturing industry continues to shift to China when China's labor force is relatively low. The spread of low-end processing plants in the manufacturing industry has resulted in low resource utilization and serious damage to the ecological environment.

2.1.4. The Development of Enterprises Ignores the Construction of Mechanisms and Systems. Chinese enterprises attach importance to the construction of enterprise culture but ignore the most basic system construction. The unreasonable supply and demand of human resources in the manufacturing industry should be focused on, and the mechanism and system should be improved to promote enterprise management innovation.

\subsection{Fuzzy MCDM}

2.2.1. Fuzzy Theory and MCDM. Fuzzy theory is the related theory of using the concept of fuzzy set and the related principle of membership function to solve fuzzy mathematical problems [7]. The fuzzy theory will soon be applied to various fields with its related development. For example, the information in natural language is fuzzy, such as "tall" and "thin." In the field of fuzzy mathematics, a membership function is a mathematical tool that can represent fuzzy sets. For example, older people form a set. Perhaps, the membership function of the elderly over 80 and 70 is 0.7 and 0.5 , respectively. In this way, a fuzzy set is constructed for all membership functions between 0 and 1 in a certain domain.

2.2.2. People are Faced with Various Options When Making Decisions. Certain criteria need to be formulated to facilitate people's comparison and selection, and these decisionmaking criteria are often not unique. For example, multiple factors should be taken into consideration when people buy a house, such as the size, price, ventilation, and lighting of the house; the perfection of nearby facilities; and the distance from the company. Similar decision-making problems that cannot completely replace each other belong to MCDM [8].

\subsubsection{The Classification of MCDM and Common MCDM} Methods. As theory develops, MCDM is categorized into two parts according to the finite scheme and infinite scheme, namely, multiattribute decision-making and multiobjective decision-making [9]. Multiattribute decision-making is to rank the schemes obtained when considering multiple objectives and decide the optimal one. Its criteria are implicit and not directly related to selection. Multiobjective decisionmaking needs to consider two or more objectives at the same 
time, and its decision criteria are directly related to the selection.

The common MCDM methods are weighted methods of simple additivity and analytic hierarchy process (AHP) [10]. AHP is widely adopted in development problems because of its simple use. It aims to decompose the complex decision-making problem according to a certain criterion; construct a hierarchical structure model according to the target layer, criterion layer, and scheme layer; establish a judgment matrix by comparing the related factors of each layer; and finally rank all schemes and select the optimal one [11]. Figure 1 presents the structural model of AHP.

The change of decision-making environment will accelerate with the increase of complexity of decision-making problems, and decision-makers will have certain limitations in their grasp and subjective evaluation of problems. The reasons are that the subjective preferences of decisionmakers are difficult to describe by simple numerical values, and most decision-making problems are difficult to quantify. The fuzzy MCDM problem based on fuzzy sets can be employed to solve the problem of uncertainty in practical decision-making.

\subsubsection{The Determination of Evaluation Weight and Index} Judgment Matrix. The determination and calculation of the evaluation weight are the most crucial for the solution of fuzzy MCDM [12]. The size of the weight represents the importance of the criteria, which is divided into subjective weighting method, objective weighting method, and combination weighting method. The subjective weight is determined by subjective evaluation based on the experience of experts in related fields. Objective weight refers to the weight calculation method of weighting each index through a decision matrix. The combination weighting method is proposed based on the advantages and disadvantages of subjective and objective weight, that is, the combination of subjective and objective weight to make the weight calculation more reasonable [13]. The index judgment matrix of the enterprise management is constructed through the evaluation index according to the results of the questionnaire analysis, as shown in Table 1 . The data $b_{i j}$ in the table indicates the relative importance of $B_{i}$ to $B_{j}$ under the judgment criteria.

2.2.5. MCDM Group Information Aggregation. An appropriate method needs to be selected to aggregate the group information after the weight information and index judgment matrix are determined [14]. If the group weight vector of experts is $V=\left\{v_{1}, v_{2}, \ldots, v_{s}\right\}$, the triangular fuzzy numbers are aggregated by the weighted average method for the left, middle, and right points. The triangular fuzzy numbers obtained by experts' overall evaluation are $X_{k}=\left(x_{1}, x_{m}, x_{n}\right), k=1,2, \ldots ., s$. The calculation equation of difference degree $D(x, y)$ for two triangular fuzzy numbers $X=\left(x_{1}, x_{m}, x_{n}\right)$ and $Y=\left(y_{1}, y_{m}, y_{n}\right)$ is as follows:

$$
D(x, y)=\sqrt{\frac{1}{3}\left[\left(x_{l}-y_{l}\right)^{2}+\left(x_{m}-y_{m}\right)^{2}+\left(x_{n}-y_{n}\right)^{2}\right]} .
$$

Equation (2) shows the calculation of similarity $S(x, y)$ between two triangular fuzzy numbers $X=\left(x_{1}, x_{m}, x_{n}\right)$ and $Y=\left(y_{1}, y_{m}, y_{n}\right)$.

$$
S(x, y)=\frac{x_{1} y_{l}+x_{1 \pi} y_{i n}+x_{n} y_{n}}{\sqrt{\left(x_{1}\right)^{2}+\left(x_{m}\right)^{2}+\left(x_{n}\right)^{2}} * \sqrt{\left(y_{l}\right)^{2}+\left(y_{m}\right)^{2}+\left(y_{n}\right)^{2}}} .
$$

The group evaluation information obtained from the aggregation of the individual judgment of experts is analyzed. The difference between the group score value and the original data is small, and the similarity degree is large, showing the effectiveness of the decision information after aggregation.

\section{Construction of the Enterprise Management Performance Evaluation System Based on AHP}

3.1. Criteria for the Construction of the Evaluation System. The construction of the performance management evaluation system needs to meet the following four criteria:

First, the principle of measurability. The relevant value of the evaluation index should be measured in a specific way, which can be in the form of accurate data or the subjective judgment of experts using uncertain methods for a specific target [15].

Second, the principle of practicality. The standard evaluation method needs to be provided to the routine purchasing department, so the evaluation index needs to use effective quantitative standards.

Third, the principle of comprehensiveness. Comprehensiveness is the most intuitive principle for the evaluation of enterprise dealer management. Index data need to be collected comprehensively to ensure the integrity of information and the reliability of decisionmaking results [16].

Fourth, the principle of logicality. A logic system in the optimization process needs to be established according to the steps of problem mining, method determination, and improvement implementation. The implementation steps have an overall sequence to ensure the correctness of logic.

Figure 2 indicates the criteria for the construction of the evaluation system.

\subsection{Primary Selection and Quantification of Evaluation} Indexes. The performance evaluation dimension of enterprise suppliers is set according to the quality index, cost index, and production capacity index proposed by supplier performance evaluation [17]. The index classification selection is conducted according to the standard operation 


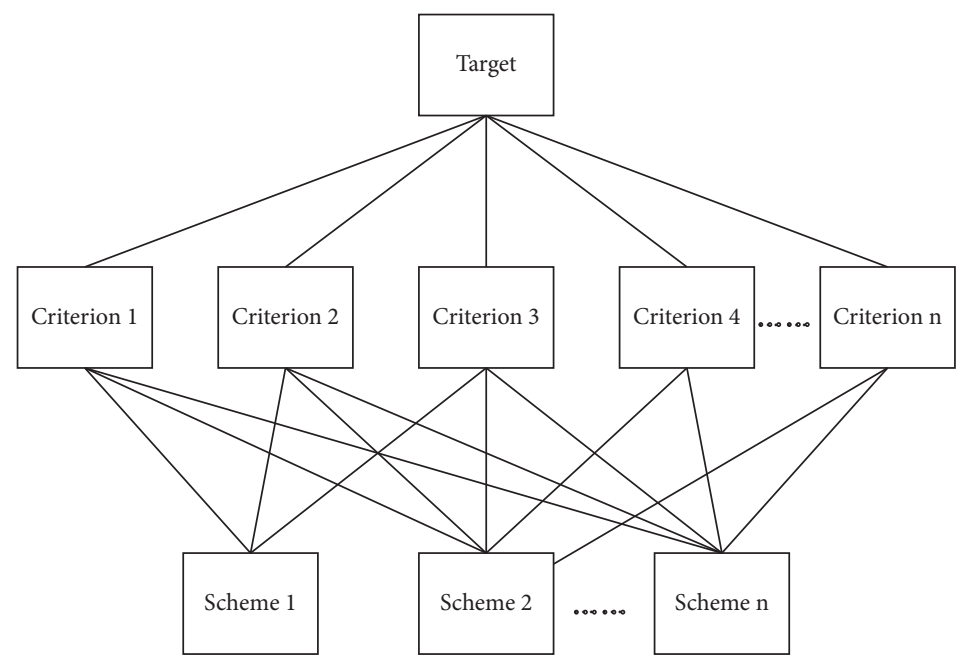

FIgURE 1: Structural model of AHP.
Target layer

Criterion layer

Scheme layer
TABLE 1: Judgment matrix of order $n$.

\begin{tabular}{lcccc}
\hline & $B_{1}$ & $B_{2}$ & $\ldots \ldots$ & $B_{\mathrm{n}}$ \\
\hline$B_{1}$ & $b_{11}$ & $b_{12}$ & $\ldots \ldots$ & $b_{1 n}$ \\
$B_{2}$ & $b_{21}$ & $b_{22}$ & $\ldots \ldots$ & $b_{2 n}$ \\
$\ldots \ldots$ & $\ldots \ldots$ & $\ldots \ldots$ & $\ldots \ldots$ & $\ldots \ldots$ \\
$B_{n}$ & $b_{n 1}$ & $b_{n 2}$ & $\ldots \ldots$ & $b_{n n}$ \\
\hline
\end{tabular}

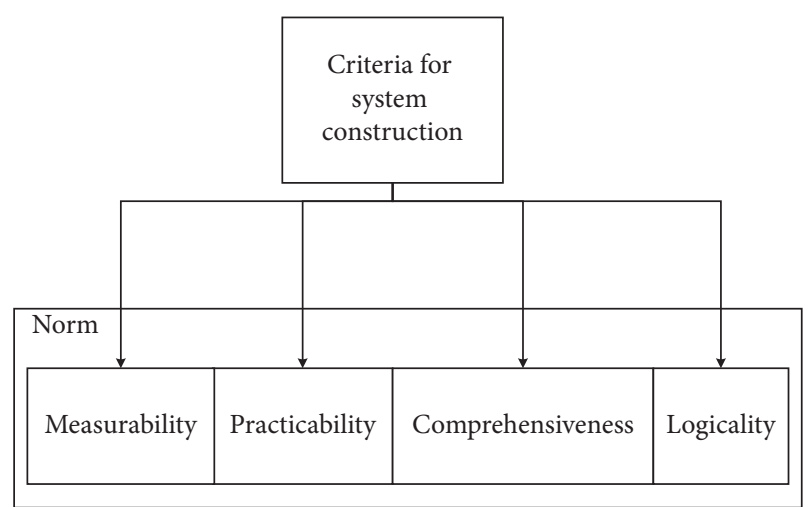

FIgURE 2: Criteria for the construction of the evaluation system.

process, and department personnel related to supplier performance evaluation are selected for discussion. Table 2 displays the established classification and index pool of enterprise supplier performance evaluation [18].

The evaluation indexes are categorized into three levels of $\mathrm{A}, \mathrm{B}$, and $\mathrm{C}$ through $\mathrm{ABC}$ classification method. The three levels are adopted to judge the decisive factors that play a key role in the final goal and the secondary factors that exert less influence on the key goal. Table 3 presents the quantitative results. In the table, 1 means that the factor is selected as the measurement index, and 0 means that it is not selected. Different models are employed to quantify and calculate the supplier evaluation index. There are five different levels for inspection: very poor, poor, general, good, and excellent. The weight of their suppliers is ranked by importance according to the production and operation status of manufacturing enterprises [19].

3.3. Building the AHP Model. According to the evaluation index determined before, Figure 3 is the analysis model diagram of the enterprise performance evaluation system based on AHP. First, weight is analyzed, and the matrix is decomposed into the form of maximum eigenvalue and eigenvector [20]. Then, the consistency test is adopted to judge the matrix logic.

\subsection{Data Collection and Data Validity Analysis}

3.4.1. Sample Data Collection. The employee data of each department of a large manufacturing enterprise is collected by questionnaire. The questionnaire results are collected through an on-site questionnaire, WeChat, and e-mail. The questionnaire has five parts, namely, the interviewees' working experience in the enterprise, the interviewees' basic personal situation, the problems existing in enterprise management innovation, the factors influencing enterprise management, and the collection of evaluation index of the enterprise management innovation ability. Overall, 226 questionnaires are distributed, and 216 are collected. 13 questionnaires with duplicate or missing data are excluded, and 203 questionnaires are valid.

3.4.2. Validation Analysis of the Questionnaire. Validity reflects the response of the questionnaire to the evaluation objectives and requirements, which is classified as content validity and structure validity [21]. After the scale of the enterprise innovation research group is modified, the factor analysis method is adopted to test the validity of the structure, so that the designed questionnaire achieves high content validity and structure validity. Reliability describes the reliability and stability of the questionnaire. Generally, Cronbach $\alpha$ coefficient is employed to measure the consistency of the results obtained by the same method for the 
TABLE 2: Classification and indexes of enterprise performance evaluation.

\begin{tabular}{lc}
\hline Classification & Indexes \\
\hline $\begin{array}{l}\text { Product quality } \\
\text { Product manufacturing cost }\end{array} \begin{array}{c}\text { Source and control of raw materials, product quality certification } \\
\text { Product service } \\
\text { Raw material logistics funds, market price increase } \\
\text { Production and manufacturing of products } \\
\text { Product technology and R\&D }\end{array}$ & $\begin{array}{c}\text { Product production technology, product production capacity, mechanical equipment } \\
\text { capacity }\end{array}$ \\
& The practicability and integrity of technology and the substitutability of technology \\
\hline
\end{tabular}

TABle 3: Quantitative results of supplier indexes.

\begin{tabular}{|c|c|c|c|c|c|}
\hline Measurement index (weight) & Bracket (1.2) & Panel (1.5) & Connector (1.1) & Administrative office (1) & Total score \\
\hline Qualified products & 1 & 1 & 1 & 0 & 3.8 \\
\hline Product quality & 0 & 0 & 1 & 1 & 2.1 \\
\hline Price competitiveness & 1 & 1 & 1 & 1 & 4.8 \\
\hline Logistics cost & 1 & 0 & 0 & 1 & 2.2 \\
\hline
\end{tabular}

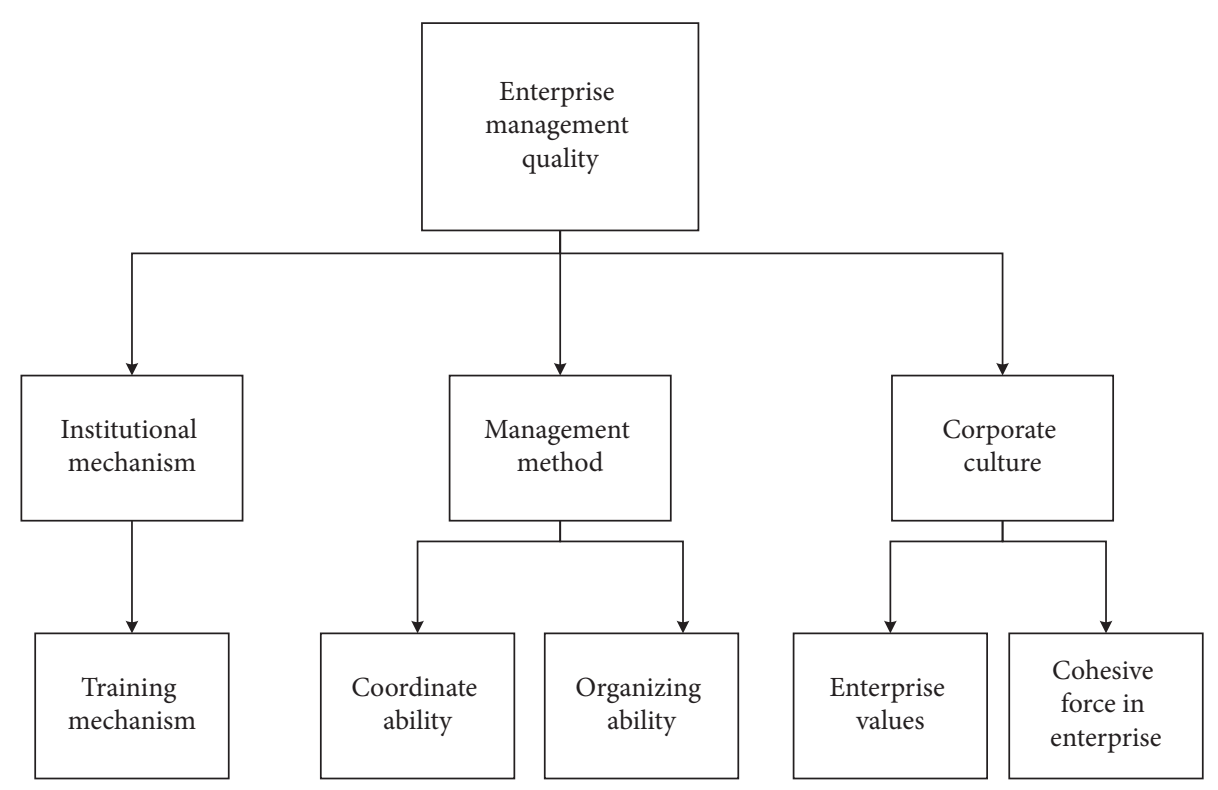

FIGURE 3: Hierarchy model diagram.

same experimental subjects. The experimental data obtained by the designed questionnaire is not ideal when the coefficient is less than 0.5; the results of the questionnaire can be accepted when the coefficient is greater than 0.6 ; the reliability of the questionnaire is very high when the coefficient is greater than 0.9 .

Confirmatory factor analysis is needed to further test the reliability and validity of the evaluation model [22]. First, factor analysis is conducted on the first-level index of the evaluation system of the management innovation ability of manufacturing enterprises. Then, the overall evaluation system is evaluated and analyzed. Only when the average variance extraction of the model is more than 0.5 , the standardized factor load is more than 0.6 , and the component reliability is more than 0.7 , can the corresponding standard of good reliability and convergence validity be reached.

\section{Analysis of Evaluation Research Results}

4.1. Analysis Results of Sample Characteristics. Figure 4(a) shows the statistical results of gender ratio, suggesting that men account for $55.67 \%$ and women account for $44.33 \%$ in the sample data; Figure 4(b) shows the statistical results of various manufacturing industries in the questionnaire statistics. The number of equipment manufacturing enterprises accounts for $20.69 \%$, biomedical enterprises for $18.72 \%$, chemical enterprises for $12.32 \%$, material manufacturing enterprises for $13.79 \%$, electronic and electrical enterprises for $19.7 \%$, and agricultural and sideline products enterprises for $14.78 \%$.

Figure 5 displays the statistical results of age and educational background. Figure 5(a) presents the proportion of all ages in the questionnaire sample. There are 44 people aged 30 and below, accounting for $21.7 \%$; 78 people aged 


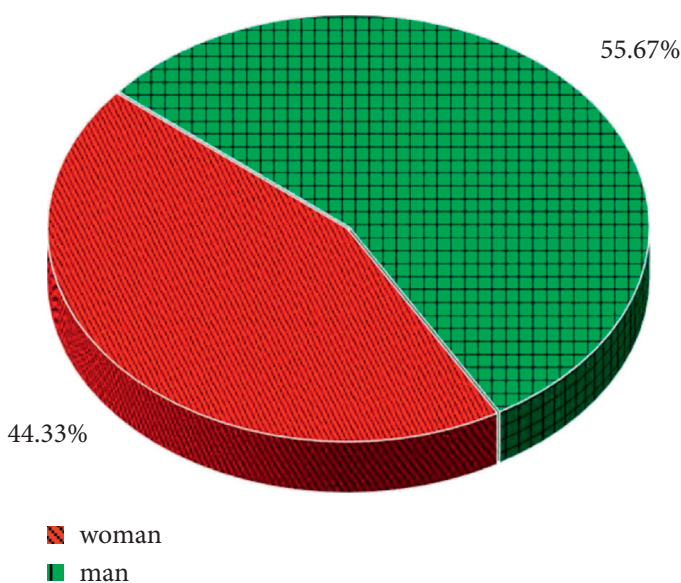

(a)

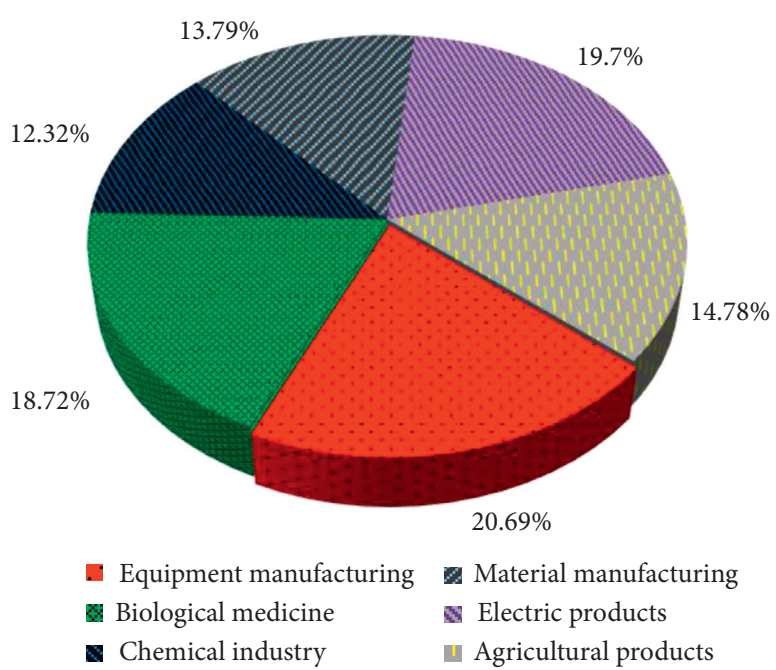

(b)

FIgURE 4: The statistical results of the gender ratio and manufacturing industries in the questionnaire sample.

$31-40$, accounting for $38.4 \%$; 62 people aged $41-50$, accounting for $30.5 \%$; 18 people aged $51-60$, accounting for $8.9 \%$; and one person over 60 years old, accounting for $0.5 \%$. Figure 5(b) shows the statistical results of the education stage. In terms of educational level, there are 25 people with a college degree, accounting for $12.3 \%$; 142 people with an undergraduate degree, accounting for $70 \% ; 34$ people with master's degrees, accounting for $16.7 \%$; and 2 people with a doctorate degree, accounting for $1 \%$.

The collection of personal information includes the years of working in the manufacturing enterprise and the positions held by the respondents. Figure 6(a) shows the statistical results of the working years of the respondents. 13 people have worked for 3-5 years, accounting for $6.4 \% ; 76$ people have worked for 6-10 years, accounting for $37.4 \%$; 64 people have worked for $11-15$ years, accounting for $31.5 \%$; 43 people have worked for 16-20 years, accounting for $21.2 \%$; and only 7 people have worked for more than 20 years, accounting for 3.4\%. In Figure 6(b), the ordinate is the position type. A represents the main person in charge, 17 persons in total, accounting for $8.4 \%$; $\mathrm{B}$ represents the person in charge of $\mathrm{R} \& \mathrm{D}, 34$ persons in total, accounting for $16.7 \%$; C represents marketing director, 41 persons in total, accounting for $20.2 \%$; D represents administrative personnel, 43 in total, accounting for $21.2 \%$; E represents the person in charge of production, 49 persons in total, accounting for $24.1 \%$; and $\mathrm{F}$ represents the person in charge of finance, 19 persons in total, accounting for $9.4 \%$.

4.2. Results of Validity Analysis. First, all variables are tested by Kaiser-Meyer-Olkin (KMO) and Bartlett's test. It is generally believed that the statistical scale is suitable for factor analysis when KMO is greater than 0.8 . The closer the $\mathrm{KMO}$ value is to 1 , the stronger the correlation among variables is, and the better the effect of factor analysis is. The $\mathrm{KMO}$ value is 0.860 , the result of Bartlett's test is 660.281 , the degree of freedom is 21 , and the $P$ value is less than 0.05
$(P \leq 0.05)$. The factor load of each item is above 0.710 , indicating that the original questionnaire has good construct validity.

Figure 7 shows the validity analysis results. The ordinate represents the validity value and the abscissa represents the degree of support for organizational management. The validities of items 1,2 , and 3 are $0.8,0.75$, and 0.9 , respectively; B represents the creativity level of organization management, in which the validities of items 1,2, and 3 are $0.5,0.85$, and, 0.76, respectively; C represents the improvement effect of organizational management, in which the validities of items 1,2 , and 3 are $0.85,0.8$, and 0.57 , respectively.

\subsection{Results of Confirmatory Factor Analysis.} Confirmatory factor analysis is conducted on the indexes of the innovation ability evaluation system of each manufacturing enterprise, so as to further test the constructed evaluation index and the effectiveness of the system. Then, the model evaluation analysis of the overall evaluation system is carried out. The test results are significant when the standardized factor load of the measurement model is greater than 0.6. The confirmatory factor analysis is conducted for enterprise organization management innovation. Figure 8 displays the results. The standardized factor load of each item of organizational management innovation is more than 0.6 and significant, the Cronbach $\alpha$ coefficient value is 0.8 , and the data analysis results meet the recommended standard, suggesting that the organizational management innovation index has good reliability and convergence validity.

4.4. Mean Value Analysis of the Management Ability Evaluation Index. Figure 9 displays the evaluation result of enterprise management ability. The average score of each firstlevel evaluation index is obtained with 5 points as the scoring standard. 3.7318 of the total average results is the average 


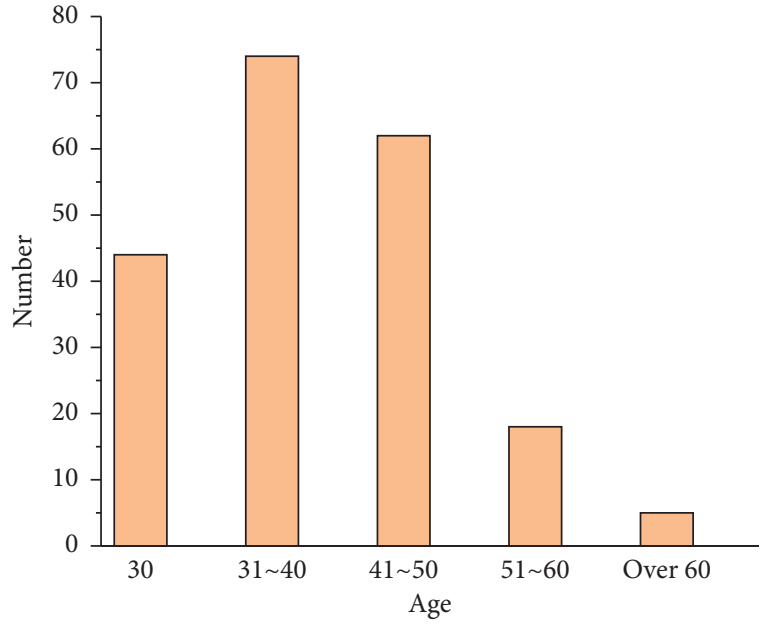

(a)

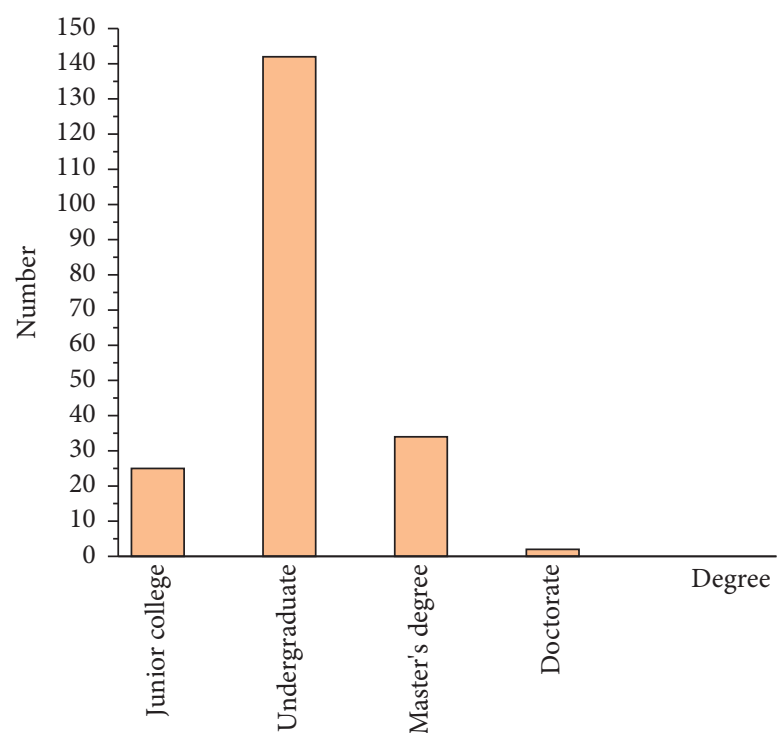

(b)

FIgURE 5: Statistical results of age and educational background in the questionnaire sample.

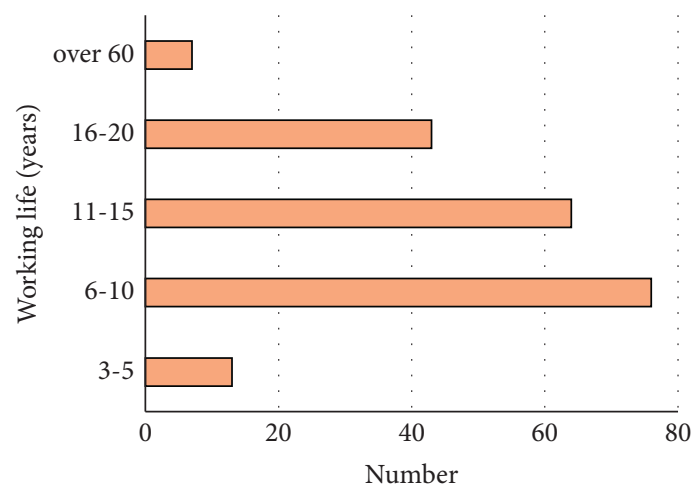

(a)

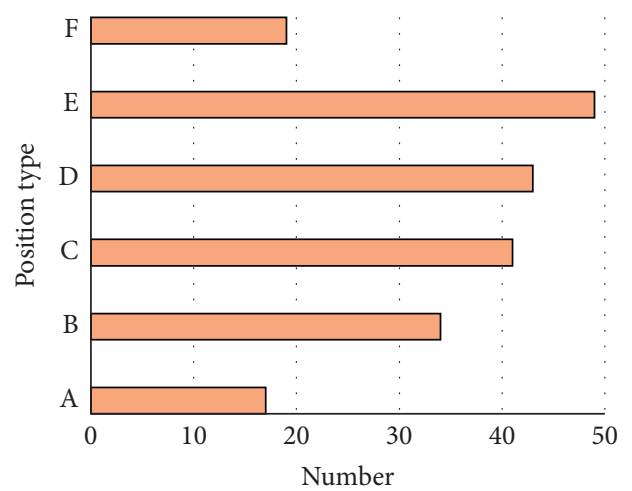

(b)

FIGURE 6: Statistical results of working hours and positions in the questionnaire sample (the ordinate).

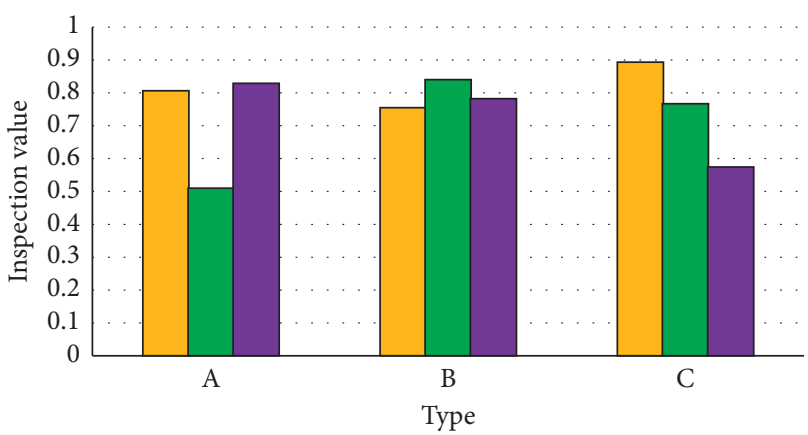

$\square$ Measurement item 1

Measurement item 2

- Measurement item 3

FIGURE 7: Result chart of validity analysis: (a) the support degree of organization management; (b) the creativity level of organization management; (c) the improvement effect of organization management.

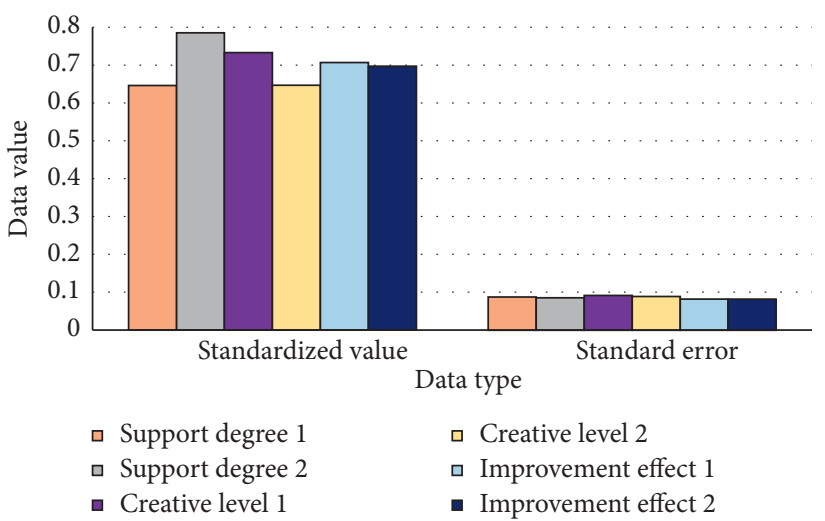

Figure 8: Confirmatory factor analysis results.

reference object, and $\mathrm{R} \& \mathrm{D}$ management of enterprises is higher than 3.7318. Enterprise marketing and production management values are slightly higher than the total average, 
and enterprise organization management value is lower than 3.7318, indicating that the R\&D management performance of large manufacturing enterprises is better and the innovation of organization management is obviously insufficient. There is still a lot of room for innovation in enterprise marketing and production. The average value of the four indexes of enterprise marketing management, enterprise R\&D support, enterprise R\&D achievement transformation efficiency, and enterprise production innovation is higher than 3.731, indicating that large manufacturing enterprises quite support marketing, $\mathrm{R} \& \mathrm{D}$, and product innovation. The results of sample statistical analysis suggest that the overall age of the person in charge of the enterprise is older; the educational background is mainly undergraduate; the enterprises lack professional management personnel; some enterprises are subject to the decision-making mechanism and are not flexible enough; and there is no long-term strategic layout in enterprise strategy formulation, which is prone to multiple disadvantages of enterprise management.

\section{Result Analysis and Discussion}

The management innovation of manufacturing enterprises has a far-reaching impact on the economic performance development of enterprises. In the current era, there are significant differences in the efficiency of management innovation among different enterprises. All large- and medium-sized enterprises have management innovation to a certain extent. However, the enterprise management innovation mode with regional competitive advantage is more diversified, because these enterprises can obtain income through industrial subsidies; that is, the industrial subsidy policy has a certain positive role in promoting. Besides, the holding form of state-owned enterprises is similar to the management innovation mode of private holding. They are mainly based on business model and industrial subsidy policies, and there are only some differences in profit samples. For example, Liu et al. [23] studied the optimal allocation of enterprise human resources and put forward the ideal allocation scheme of organization to human resources, which has excellent application value for enterprise human management innovation. Li et al. [24] studied the impact of intermediary effect on enterprise innovation and analyzed the potential factors of enterprise risk-taking as an intermediary, which is of great significance for enterprise management innovation and enterprise sustainable development. Through the analysis of the influencing factors of enterprise management innovation ability, Idewele et al. [25] confirmed that enterprises can strengthen management innovation ability through active control in case of operation and management difficulties. Regarding the research on big data, Chen et al. [26] proposed a method to solve the information redundancy of blockchain, analyzed the shortcomings of blockchain and its causes, verified the feasibility of applying blockchain to enterprise personnel information management, and provided a new direction for the research on enterprise management innovation. Lv et al. [27] constructed the fuzzy mean clustering algorithm theory based on objective function by using K-means and fuzzy theory in

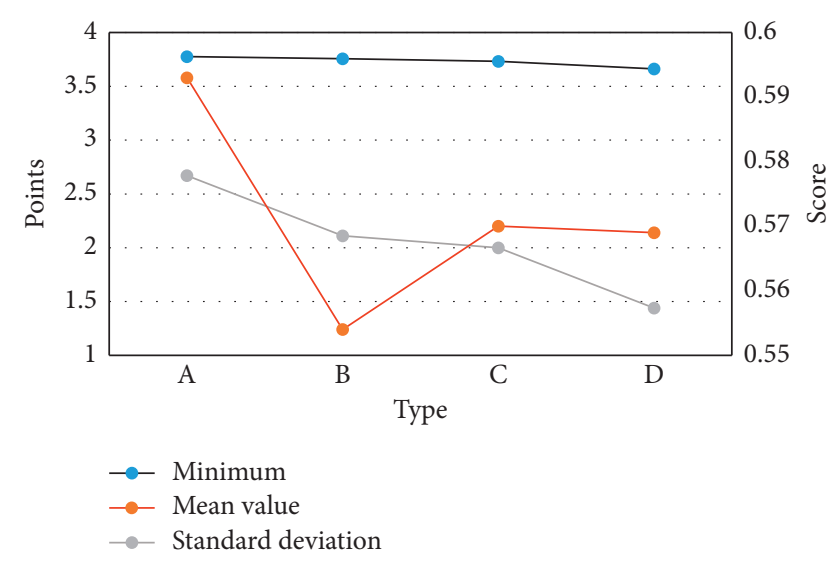

FIGURE 9: Evaluation results of enterprise management capability index (the abscissa in the figure shows the type of enterprise management capability. A represents enterprise R\&D management, B represents enterprise marketing management, C represents enterprise production management, and $\mathrm{D}$ represents enterprise organization management).

big data analysis technology, which can significantly reduce the network data transmission performance delay, change the path, and effectively inhibit the spread of congestion. Subsequently, Lv et al. [28] used blockchain technology to study the privacy and security of UAV big data. The performance evaluation results show that the proposed UAV big data privacy protection scheme based on blockchain technology has low computing cost in key generation, encryption, and decryption. For the application of big data in $6 \mathrm{G}$ mobile communication, Lv et al. [29] studied large-scale Internet of things devices. The results show that $6 \mathrm{G}$ technology leads to different energy efficiency of data transmission for different interference thresholds in the energy consumption analysis. To sum up, factors such as creativity, initiative, and opportunity grasp can be considered to investigate the relationship between enterprises and management innovation ability, which is similar to investigating the relationship between management innovation ability and management.

\section{Conclusion}

The management innovation ability of the domestic traditional manufacturing industry is taken as the research object. The theory is combined with practice to discuss the theoretical research of enterprise innovation management, which has practical reference value for improving the management innovation ability of manufacturing enterprises. First, the evaluation index system of manufacturing enterprise management innovation ability is designed based on the theoretical integration and the characteristics of manufacturing enterprises after the study of previous literature. Then, the composition and weight of the index system are determined by the way of expert scoring. Unlike the previous research, the main innovation is to focus on the research of enterprise ability and study the enterprise production management system, enterprise organization and coordination ability, and information technology 
innovation level from the perspective of enterprise management ability. There are still some deficiencies in the research on the evaluation of management innovation ability of manufacturing enterprises due to limited knowledge and experience, mainly in the following two aspects. First, the qualitative and quantitative indexes of the index system are not comprehensive enough and need to be improved in a later stage. Second, the data collected are limited. Compared with the huge number of manufacturing enterprises, more data of manufacturing enterprises can be added in later research for comparative analysis.

\section{Data Availability}

The data used to support the findings of this study are available from the corresponding author upon request.

\section{Conflicts of Interest}

The authors declare no conflicts of interest.

\section{References}

[1] J. Xu and F. Liu, "Nexus between intellectual capital and financial performance: an investigation of Chinese manufacturing industry," Journal of Business Economics and Management, vol. 22, no. 1, pp. 217-235, 2021.

[2] Z. Li, "Evaluation research on green degree of equipment manufacturing industry based on improved particle swarm optimisation algorithm," International Journal of ReasoningBased Intelligent Systems, vol. 12, no. 3, pp. 217-221, 2020.

[3] C. C. Qi, "Big data management in the mining industry," International Journal of Minerals, Metallurgy and Materials, vol. 27, no. 2, pp. 131-139, 2020.

[4] Y. Su and Y. Q. Yu, "Spatial agglomeration of new energy industries on the performance of regional pollution control through spatial econometric analysis," The Science of the Total Environment, vol. 704, Article ID 135261, 2020.

[5] M. N. Mohammedali, M. Rasheed, S. Shihab, T. Rashid, and S. H. Abed Hamed, "Fuzzy set technique application: the solar cell," Journal of Al-Qadisiyah for Computer Science and Mathematics, vol. 13, no. 1, pp. 62-69, 2021.

[6] Z. Khan, M. Gulistan, R. Hashim, N. Yaqoob, and W. Chammam, "Design of S-control chart for neutrosophic data: an application to manufacturing industry," Journal of Intelligent \& Fuzzy Systems, vol. 38, no. 4, pp. 4743-4751, 2020.

[7] X. Liu, G. Tian, A. M. Fathollahi-Fard, and M. Mojtahedi, "Evaluation of ship's green degree using a novel hybrid approach combining group fuzzy entropy and cloud technique for the order of preference by similarity to the ideal solution theory," Clean Technologies and Environmental Policy, vol. 22, no. 2, pp. 493-512, 2020.

[8] M. Riaz, N. Çagman, N. Wali, and A. Mushtaq, "Certain properties of soft multi-set topology with applications in multi-criteria decision making," Decision Making: Applications in Management and Engineering, vol. 3, no. 2, pp. 70-96, 2020.

[9] L. Wang and N. Li, "Pythagorean fuzzy interaction power Bonferroni mean aggregation operators in multiple attribute decision making," International Journal of Intelligent Systems, vol. 35, no. 1, pp. 150-183, 2020.
[10] S. Biswas, "Measuring performance of healthcare supply chains in India: a comparative analysis of multi-criteria decision making methods," Decision Making: Applications in Management and Engineering, vol. 3, no. 2, pp. 162-189, 2020.

[11] R. Gharizadeh Beiragh, R. Alizadeh, S. Cavallaro, S. Zolfani, R. Bausys, and A. Mardani, "An integrated multi-criteria decision making model for sustainability performance assessment for insurance companies," Sustainability, vol. 12, no. 3, p. 789, 2020.

[12] M. Bakır and Ö. Atalık, "Application of fuzzy AHP and fuzzy MARCOS approach for the evaluation of e-service quality in the airline industry," Decision Making: Applications in Management and Engineering, vol. 4, no. 1, pp. 127-152, 2021.

[13] M. Hamka, "Application of fuzzy preference relations method in AHP to improve judgment matrix consistency," IOP Conference Series: Materials Science and Engineering, vol. 821, no. 1, 2021.

[14] Y. Hu, W. Xie, J. An, J. Yao, and W. Ma, "Research on evaluation index system of autonomous and controllable capability of aerospace test and launch system," IOP Conference Series: Earth and Environmental Science, vol. 692, no. 2, 2021.

[15] A. Mehdic, T. Gunton, and M. Rutherford, "Assessing the role of subjective judgment and science in environmental impact assessment: implications and options for reform," Journal of Environmental Planning and Management, vol. 63, no. 10, pp. 1771-1790, 2020.

[16] R. Garcia-Retamero, D. Petrova, E. T. Cokely, and A. Joeris, "Scientific risk reporting in medical journals can bias expert judgment: comparing surgeons' risk comprehension across reporting formats," Journal of Experimental Psychology: Applied, vol. 26, no. 2, pp. 283-299, 2020.

[17] S. Wenkel, K. Alhazmi, T. Liiv, S. Alrshoud, and M. Simon, "Confidence score: the forgotten dimension of object detection performance evaluation," Sensors, vol. 21, no. 13, p. 4350, 2021.

[18] J. Schlauwitz and P. Musilek, "Dimension-wise particle swarm optimization: evaluation and comparative analysis," Applied Sciences, vol. 11, no. 13, p. 6201, 2021.

[19] A. R. Verde, M. M. deOcaJ, S. R. Accordino, L. M. Alarcon, and G. A. Appignanesi, "Structural aspects of an energy-based water classification index and the structure-dynamics link in glassy relaxation," The European Physical Journal E, vol. 44, no. 4, pp. 1-10, 2021.

[20] Z. Alimoradi, F. Golboni, M. D. Griffiths, A. Broström, C.-Y. Lin, and A. H. Pakpour, "Weight-related stigma and psychological distress: a systematic review and meta-analysis," Clinical Nutrition, vol. 39, no. 7, pp. 2001-2013, 2020.

[21] K. R. Fox, J. A. Harris, S. B. Wang, A. J. Millner, C. A. Deming, and M. K. Nock, "Self-injurious thoughts and behaviors interview-revised: development, reliability, and validity," Psychological Assessment, vol. 32, no. 7, pp. 677-689, 2020.

[22] D. Sharma and P. Chandra, "Linear regression with factor analysis in fault prediction of software," Journal of Interdisciplinary Mathematics, vol. 23, no. 1, pp. 11-19, 2020.

[23] P. Liu, W. Qingqing, and W. T. Liu, "Enterprise human resource management platform based on FPGA and data mining," Microprocessors and Microsystems, vol. 80, Article ID 103330, 2021.

[24] R. Li, Y. Cui, and Y. Zheng, "The impact of corporate strategy on enterprise innovation based on the mediating effect of corporate risk-taking," Sustainability, vol. 13, no. 3, p. 1023, 2021. 
[25] I. O. E. Idewele, R. A. Andah, and M. Ridwan, "The effect of enterprise on managerial innovation capacity," Budapest International Research and Critics Institute (BIRCI-Journal): Humanities and Social Sciences, vol. 4, no. 2, pp. 2643-2657, 2021.

[26] J. Chen, Z. Lv, and H. Song, "Design of personnel big data management system based on blockchain," Future Generation Computer Systems, vol. 101, pp. 1122-1129, 2019.

[27] Z. H. Lv, Q. Liang, K. Cai, and Q. Wang, "Big data analysis technology for electric vehicle networks in smart cities," IEEE Transactions on Intelligent Transportation Systems, vol. 22, no. 3, pp. 1807-1816, 2020.

[28] Z. Lv, L. Qiao, and M. S. Choi, "Analysis of using blockchain to protect the privacy of drone big data," IEEE Network, vol. 35, no. 1, pp. 44-49, 2021.

[29] Z. Lv, R. Lou, J. Li, A. K. Singh, and H. Song, "Big data analytics for 6G-enabled massive Internet of things," IEEE Internet of Things Journal, vol. 8, no. 7, pp. 5350-5359, 2021. 